\title{
Encephalocele: know it to deal with it
}

\author{
Nilkanth Laxman Pal ${ }^{1}$, Ambika Sumeet Juwarkar ${ }^{1 *}$ and Sanjaya Viswamitra ${ }^{2}$
}

\begin{abstract}
Background: Encephaloceles refer to the herniation of intracranial contents through the defect in the dura and calvarium. This article aims to equip the radiologists with all the necessary information to approach a case of encephalocele in a systematic manner and report in an organized format. Thus reduce the reporting time without overlooking any detail.

Main text: An extensive literature review was performed searching through the standard textbooks and electronic databases to obtain thorough information on the various encephaloceles particularly from a radiological point of view. The author's observations were also incorporated in the review. Among the available imaging modalities, magnetic resonance imaging is the most versatile and considered the imaging modality of choice because of superior anatomic resolution in the characterization of central nervous system malformation. This study provides the reporting radiologist with a methodical guide to approach a case of encephalocele discussing the imaging protocol, relevant anatomy, classification, associated abnormalities, and imaging prognostic factors.

Conclusion: Encephalocele has always been a subject of predicament for radiologists. Understanding the relevant terminologies, anatomy, imaging protocols, classification, associated malformations/anomalies, and imaging prognostic factors will help to methodically approach each case and provide a systematic and comprehensive report.
\end{abstract}

Keywords: Reporting approach, Encephalocele, Sincipital, Occipital, Nasofrontal, Nasoethmoidal, Transethmoidal, Nasal glioma, Nasal dermoid

\section{Background}

Encephalocele refers to the herniation of intracranial contents through the defect in the dura and calvarium [1]. Encephalocele is a rare entity in routine radiology practice; hence, a radiologist challenged with a case of cephalocele may find oneself lacking appropriate knowledge and reporting skills required to provide an optimal report.

An adequate understanding of the imaging protocol, relevant anatomy, classification, associated abnormalities, and imaging prognostic factors is required to provide a complete report. This article aims to equip the radiologists with all the necessary information to approach a case of encephalocele in a systematic manner

\footnotetext{
* Correspondence: Ambika_juwarkar@yahoo.com

1 Department of Radio-diagnosis, Goa Medical College, Bambolim, Goa 403 202, India

Full list of author information is available at the end of the article
}

and report in an organized format. Thus reduce the reporting time without overlooking any detail.

Based on a review of the literature and 37 personal observations, the authors discuss the neuroradiological presentation of various encephaloceles and suggest a reporting template to approach cases of encephaloceles. Brief discussion of the etiology and relevant embryology is also done.

\section{Main text \\ Etiology}

The etiology of congenital encephaloceles is not fully understood and is likely to be multifactorial with the involvement of the genetic and environmental factors. Encephaloceles are considered to be a spectrum of neural tube defects caused due to failure of neurulation, i.e., failure of the neural tube closure $[2,3]$. However, this theory does not explain the presence of well-formed 
neural structures within the herniated sac since brain tissue is formed after the closure of the neural tube. Hence, some authors have proposed cephalocele to be a post neurulation event $[4,5]$. These post neurulation theories suggest that failure of mesodermal migration into the midline leads to herniation of the brain matter. This theory best explains the distorted, stretched appearance of the neuroparenchyma adjacent to the calvarial defect. During the author's observation, many cases, particularly the occipital types, did show stretched and distorted appearance of the brain adjacent to the cranial vault defect supporting the post neurulation theory. Skull base encephaloceles can be due to primary osseous defect, failure of induction of the bone secondary to defective closure of the neural tube, due to lack of fusion of ossification centers, or due to persistent craniopharyngeal canal [6]. Some encephalocele cases are acquired either post traumatic, post-surgical (iatrogenic), related to erosion from infection/tumors, or idiopathic (spontaneous).

Clinical presentations vary depending on each major subtype of encephalocele. Most of the patients present with swelling in the head region, depending on the location and size of the encephalocele. Most of the frontoethmoidal encephalocele present with a clinically visible lump at the root of the nose. Some degrees of facial disfigurement may accompany these patients like hypertelorism and proptosis. Basal encephalocele is internal and may present with swelling in the nasal cavity or nasopharyngeal region with varying degrees of obstruction, epistaxis, and CSF rhinorrhoea. Patients can also present with seizures, developmental delay, vision impairment, ataxia, microcephaly, spastic paraplegia, and features of raised intracranial pressure $[1,6,7]$.

\section{Embryological anatomy of nasofrontal region}

Familiarizing with the anatomy is critical for reporting a case of an encephalocele because it helps to identify certain anatomic landmarks that delineate the exact location of the encephalocele. The confounding locationbased classification of encephaloceles (especially anterior encephaloceles) is easy to understand and apply if one has an adequate grasp of the anatomy before reporting. Figure 1 shows the diagrammatic representation of the embryological anatomy and events at the nasofrontal area. Fonticulus frontalis is the temporary space between nasal and frontal bones, which fuses later forming a frontonasal suture. Foramen cecum is the point of union of the frontal crest with the ethmoidal bone located anterior to the crista galli. Prenasal space is the temporary space below the foramen cecum between nasal bones anteriorly and developing nasal cartilage posteriorly, which gets obliterated early in life. During early life, a dural diverticulum extends into the prenasal space via the foramen cecum and regresses later. Nasofrontal masses (cephalocele, nasal glioma, dermoid, epidermoid, and dorsal dermal sinus) occur due to faulty regression of the embryologic dural diverticulum from the prenasal space $[7,8]$ as explained in Fig. 1.

\section{Radiological approach to report a case of encephalocele Imaging}

MRI (magnetic resonance imaging) is unequivocally the modality of choice for imaging a case of encephalocele. MRI helps to delineate the location of the encephalocele, characterize the hernia sac (based on the size, contents, and the status of the herniated neuroparenchyma), and also identify other associated intracranial malformation. All the above factors aid in preoperative planning and prognostication. CT (computed tomography) may also be used to display the bone anatomy especially in cases of sincipital encephaloceles.

Routine MRI sequences T1- and T2-weighted sequences in sagittal, axial, and coronal planes, and FLAIR (fluid-attenuated inversion recovery sequence) in axial plane to be performed in all patients. In the case of occipital cephalocele, the sagittal and axial images are extremely useful to delineate the calvarial defect, hernia sac, and its contents. MR venogram and angiogram are needed to ascertain the relation of the dural sinuses and vessels with the cephalocele. This information is crucial in preoperative planning to avoid intraoperative damage to sinuses/vessels and potential ischemia following surgery. In cases of sincipital cephaloceles, coronal and sagittal images are indispensable to know the relation with important landmarks like crista galli.

Additional sequences required MPRAGE (magnetization prepared rapid gradient echo sequence) to identify various neuronal migrational anomalies. Coronal heavily weighted T2-weighted images are required while addressing fronto-ethmoidal pathologies to delineate tracts and intracranial connections while differentiating nasal glioma, dorsal dermal sinus, and true encephalocele. We realized MR venogram is not necessarily required in patients with anterior cephaloceles. Diffusion-weighted images are not required in preoperative imaging. Since most of our patients are young and some also need sedation, imaging should be tailored according to the need and location of cephaloceles. CT scan is required to correctly assess the dimensions of the calvarial defect for appropriate surgical planning.

\section{Location}

The occurrence of encephalocele is rare, reported being one in every 4000 live births. The most common location is occipital (75\%), followed by frontoethmoidal 

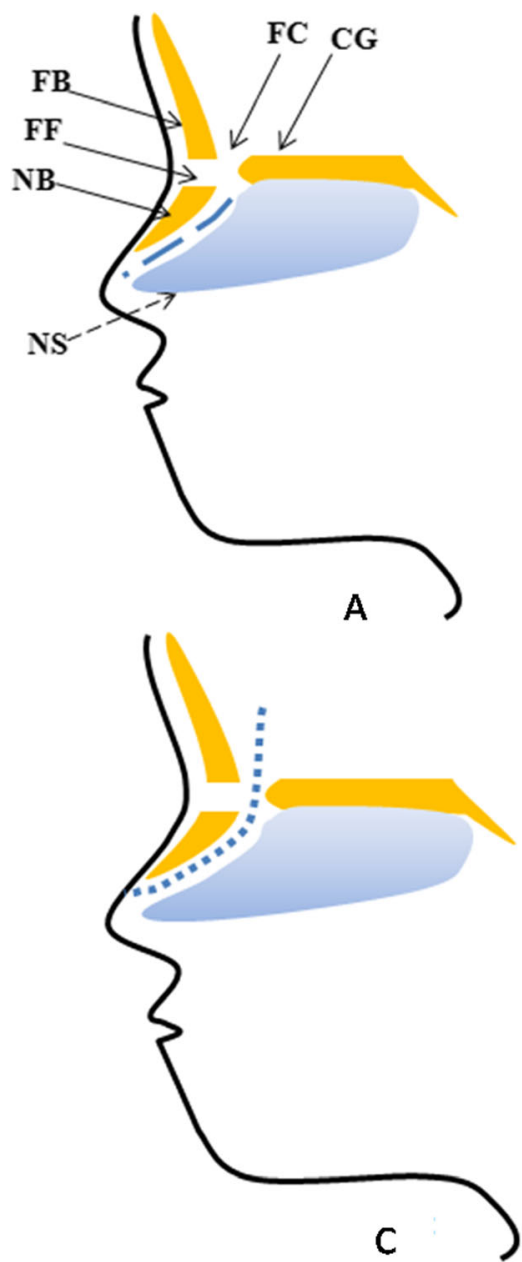
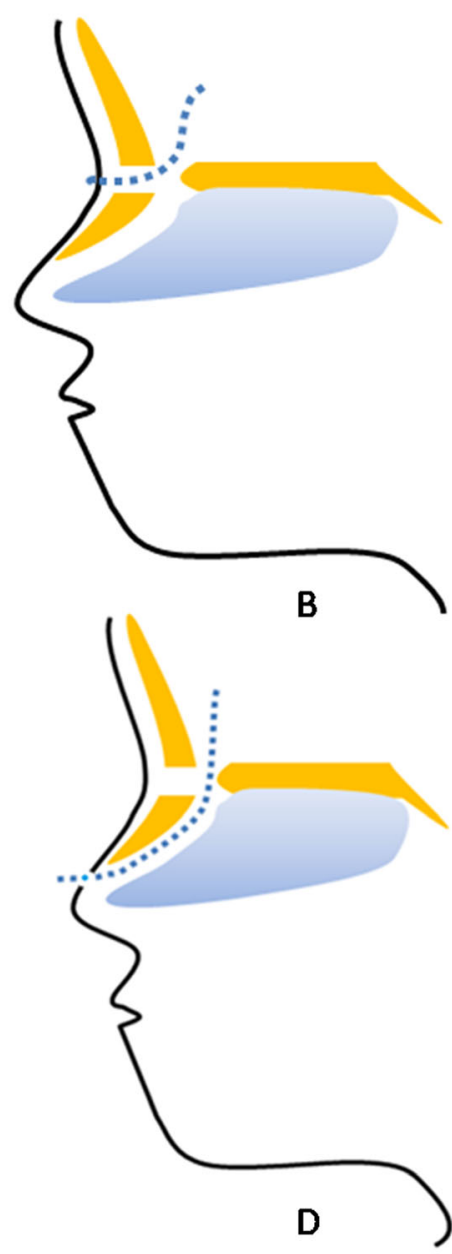

Fig. 1 Diagrams showing the anatomy of the nasofrontal region and its related pathologies. a Normal anatomy. Frontal bone (FB), fonticulus frontalis (FF), nasal bone (NB), nasal septum (NS), foramen cecum (FC), prenasal space (dotted line), and crista galli (CG). It is believed that during development, the dura mater projects through the fonticulus frontalis or more inferiorly into the prenasal space. This dural element normally regresses and its faulty regression leads to congenital nasofrontal masses. b Nasofrontal encephalocele. The dotted line shows the path for the development of nasofrontal encephalocele and has a connection with the intracranial structures. If there is no connection between herniated content and intracranial structures, it is called as extra-nasal glioma. c Nasoethmoidal encephalocele. The dotted line shows the path for the development of nasoethmoidal encephalocele and has a connection with the intracranial structures. If there is no connection between herniated content and intracranial structures, it is called an intra-nasal glioma. d Dural dermal sinus. Linear tract (dotted line) connecting intracranial structures to the dermal opening. Dermoid or epidermoid cysts may form along the dermal sinus tract due to the desquamation of tissue lining the tract

(15\%) and basal (10\%). The parietal encephalocele is rare $[1,7]$.

a. Anterior encephaloceles are located anterior to the bregma. They are further subdivided based on their location into sincipital (which occur in the region of the bridge of the nose) and basal types (which occur in relation to the cribriform plate and sphenoid sinus) $[9,10]$.

Sincipital encephaloceles are categorized into two main subtypes: frontoethmoidal and interfrontal. Interfrontal occurs between bregma and nasal bone.
Interfrontal encephaloceles are often seen in the midline in the inferior part of the metopic suture; however, in rarer events it can be paramedian in location [9, 11] (Fig. 2). Most frontoethmoidal encephaloceles occur through the foramen cecum located anterior to crista galli. Frontoethmoidal encephaloceles are further subdivided into nasofrontal, nasoethmoidal, and nasoorbital types based on their relationship with nasal bone and the nasal cartilage $[9,12]$. Nasofrontal encephalocele occurs through fonticulus frontalis, and the hernial sac is located above/anterior to the nasal bone (Fig. 3). Nasoethmoidal encephalocele herniates through the foramen cecum into the prenasal space 

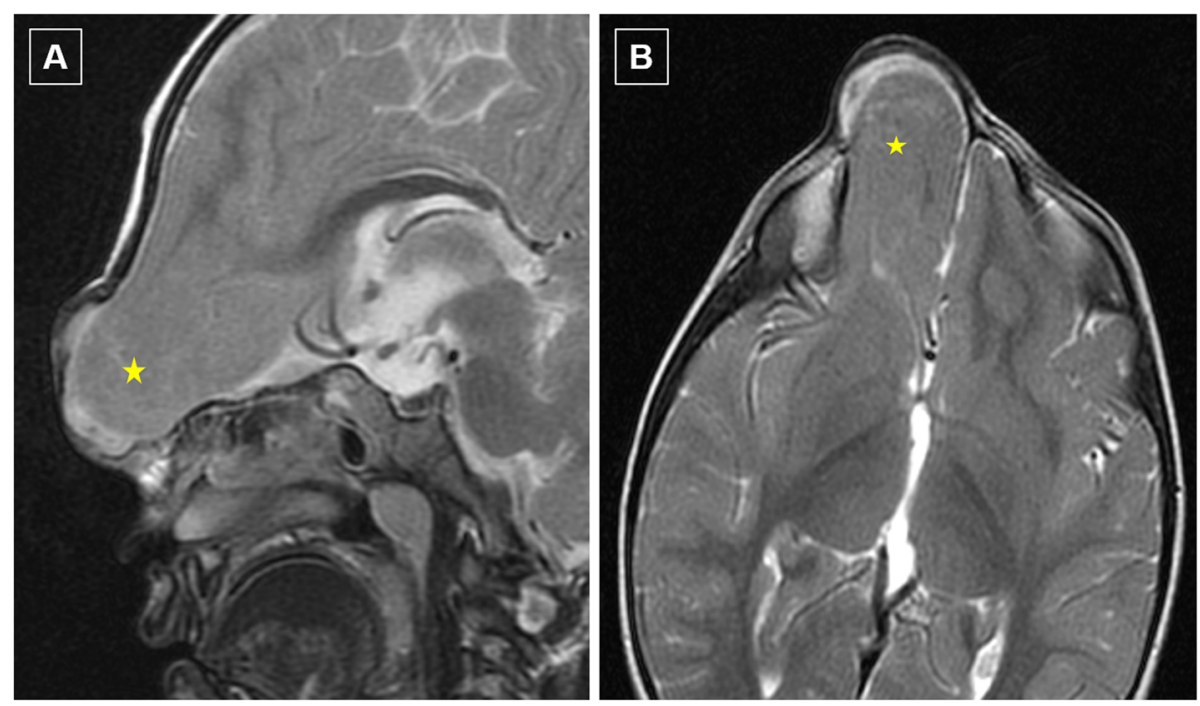

Fig. 2 Paramedian frontal encephalocele. (a) (T2-weighted sagittal) and (b) (T2-weighted axial) images show herniation of dysplastic brain (star) through the frontal bone on the right side. The herniated content is located in a paramedian location which is an unusual position for the sincipital encephalocele

(nasal cavity) located between nasal bones and nasal septum/cartilage (Fig. 4). Nasoorbital type, the rarest among the three is located along the medial orbit wall between the frontal process of the maxilla and lacrimal bone. Thus, the cephalocele passes through the lamina cribrosa, the ethmoid, and the lamina papyracea into the orbits (Fig. 4) [9, 13-15].
Basal encephaloceles occur in relation to the cribriform plate and sphenoid sinus and are divided into transethmoidal, sphenoethmoidal, sphenoorbital, and transsphenoidal types. If the herniation occurs through a defect in the cribriform plate it represents a transethmoidal encephalocele (Fig. 5). Such encephalocele projects into the nasal cavity [15-17]. Spheno-orbital type
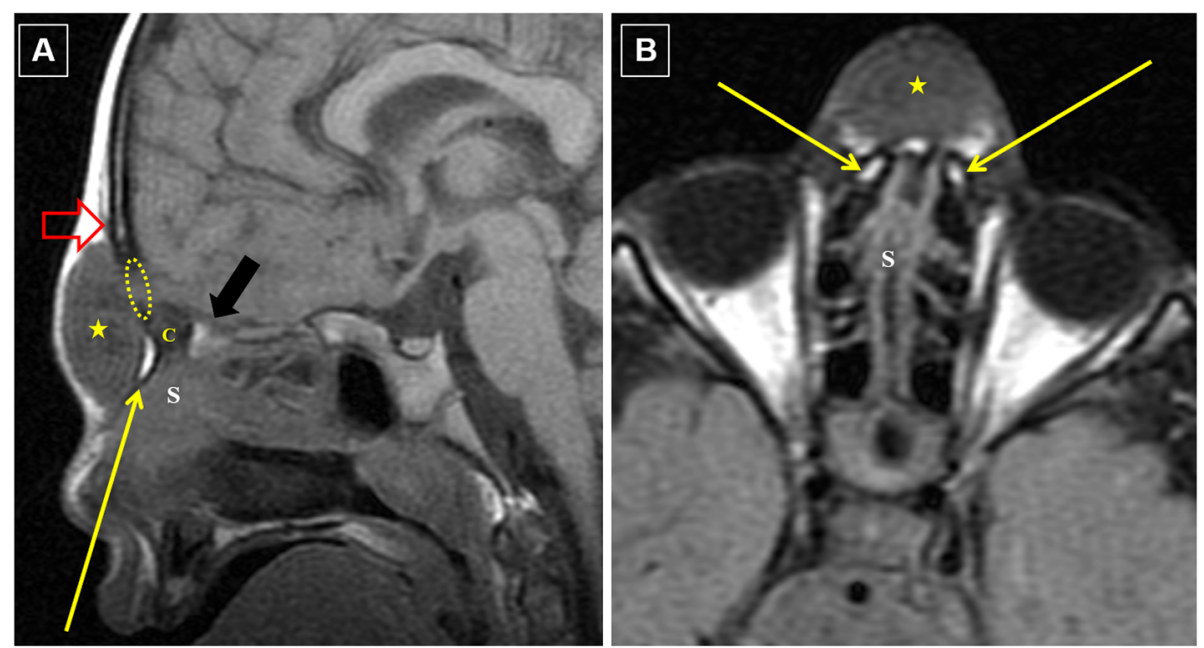

Fig. 3 Nasofrontal encephalocele. (a) (T1-weighted sagittal) and (b) (T1-weighted axial) images show herniation of intracranial content through the nasofrontal suture (fonticulus frontalis) shown by the dotted circle with the frontal bone (open arrow) seen superiorly and nasal bone (long arrow) inferiorly. These bones are identified by their fatty marrow. No herniation is seen through the foramen cecum (labeled C) located anterior to the crista galli (short arrow) which is also identified by its fatty marrow. Note the encephalocele sac (star) is noted anterior to the nasal bone (long arrow). No herniation through the foramen cecum and location anterior to the nasal bone differentiate it from the nasoethmoidal variant. Although all frontoethmoidal encephalocele (nasofrontal, nasoethmoidal, and nasoorbital types) usually herniate through the foramen cecum, in this case of nasofrontal encephalocele, no herniation is seen through the foramen cecum. 


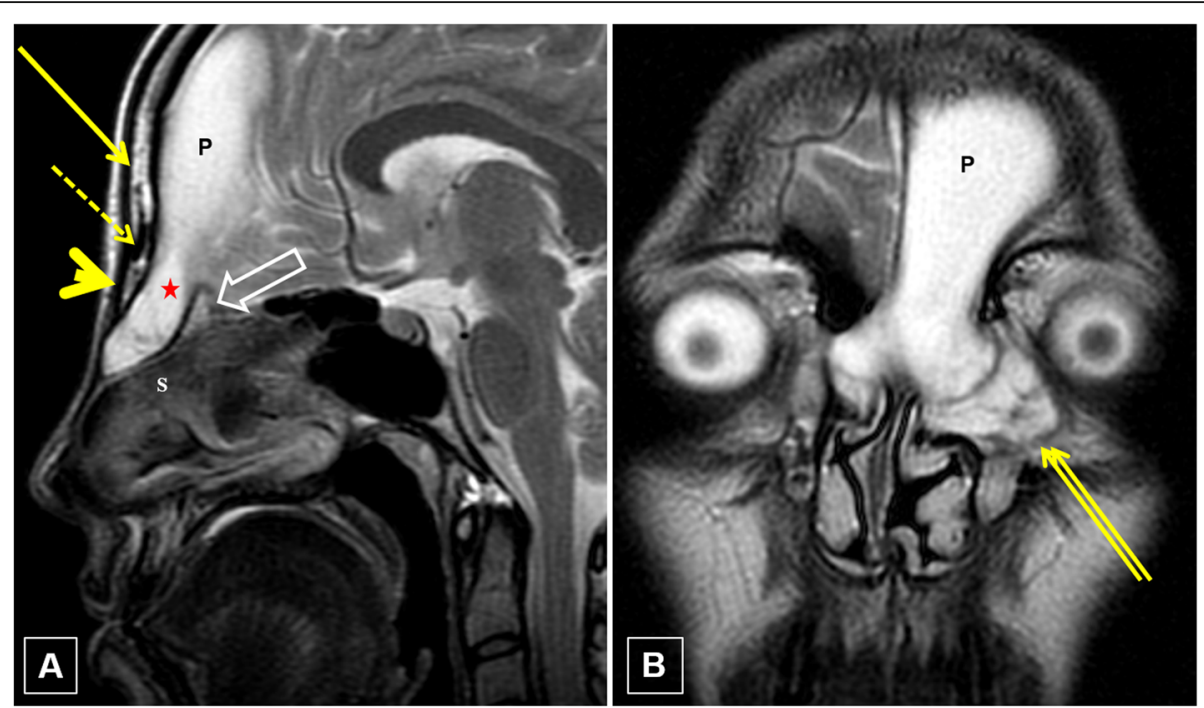

Fig. 4 Nasoethmoidal and nasoorbital encephalocele. a (T2-weighted sagittal) image shows herniation of the brain content into the prenasal space through foramen cecum (star) anterior to crista galli (open arrow). Prenasal space is bounded anteriorly by nasal bone (arrowhead) and posteriorly by nasal septum (S). Nasofrontal suture (dotted arrow) is seen between frontal bone (long arrow) and nasal bone (arrowhead). Note that the herniated content has undergone gliosis appearing hyperintense on T2-weighted images with a porencephalic cyst in the adjacent frontal lobe (P). b (T2-weighted coronal) image: Note the nasoorbital extent of this herniated sac (double arrow)

of encephalocele passes through the superior orbital fissure to lie posterior to the globe and results in unilateral exophthalmos [18]. This is the type that most commonly although not necessary is associated with neurofibromatosis. Sphenoethmoidal type extends through the sphenoid and ethmoid bones [18]. Transsphenoidal variant occurs through the floor of the sella. A transsphenoidal cephalocele splays the sphenoid bone, displacing the cavernous sinus laterally, and is positioned anterior to the dorsum sella [15-17]. Abiko et al. [19] further divided transsphenoidal meningo-encephalocele into two types: the intrasphenoidal and the true transsphenoidal. The first one describes meningoencephalocele extending into the sphenoid sinus but restricted by its floor. The latter describes cephalocele traversing the floor of the sphenoid sinus and protruding into the nasal cavity or nasopharynx. Important structures such as the pituitary gland, optic nerves, optic
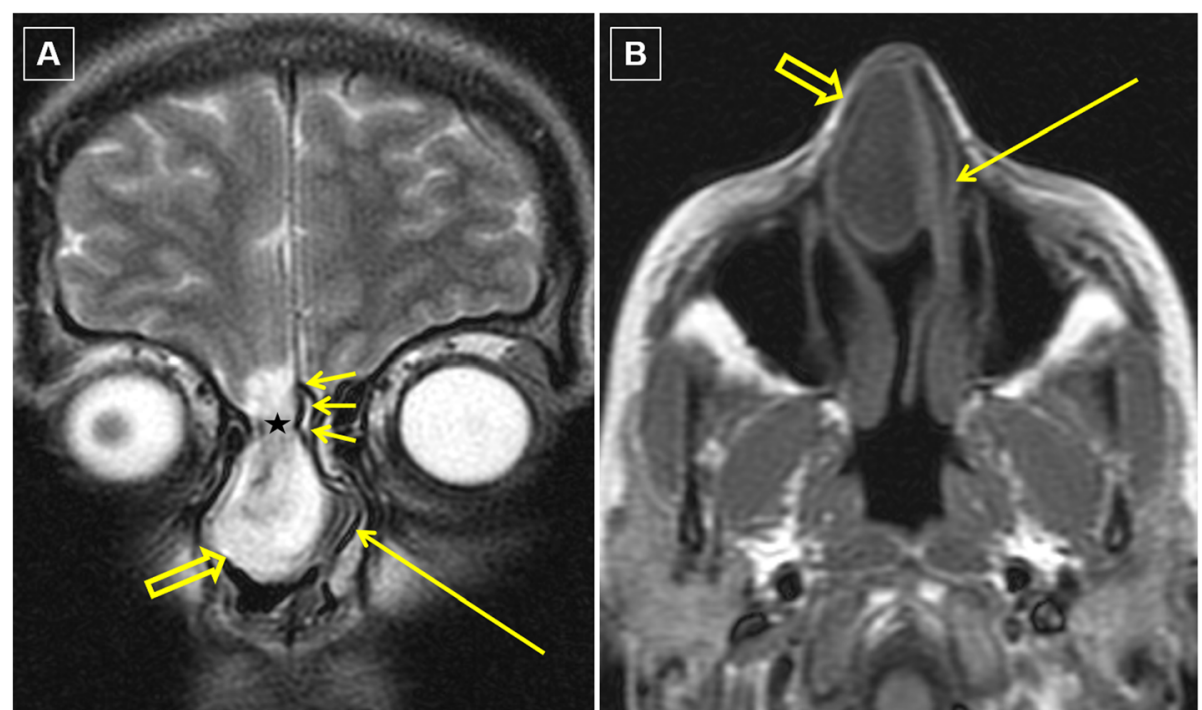

Fig. 5 Transethmoidal encephalocele. a (coronal T2 weighted) image shows herniation of intracranial content through the defect in the cribriform plate (star) seen lateral to the cribriform plate (short arrows). b (axial T1 weighted) image: Herniated content shown by an open arrow is displacing the nasal septum (long arrow) to the contralateral side 
Table 1 Summarizing the classification of encephaloceles

- Occipital
- Sincipital
Frontoethmoidal
- Nasofrontal
- Nasoethmoidal
- Nasoorbital
Interfrontal
Associated with craniofacial cleft
- Convexity
- Basal

chiasma, and anterior $2 / 3$ of ventricles need to be evaluated in transsphenoidal cephalocele [15-17].

b. Parietal encephaloceles are located between bregma and lambda [9] (Fig. 6).

c. Occipital encephaloceles occur between the lambda and foramen magnum typically in midline [9]. The bony defect may be confined to the occipital bone or descend to involve the posterior lip of the foramen magnum. They are further divided into supratorcular and infratorcular types based on their relation to torcular Herophili [20].

Classification of the encephaloceles $[9,12]$ is summarized in Table 1. Occipital encephaloceles are more common than sincipital ones. Sincipital encephaloceles are more common in South and Southeast Asian populations whereas the occipital encephaloceles are more common in the Western population without significant gender difference [21, 22].

\section{Size of the calvarial defect and the herniated sac}

The approximate length of the calvarial defect needs to be mentioned. The dimensions of the sac need to be defined in the report $(\mathrm{AP} \times \mathrm{TR} \times \mathrm{CC})$. The size of the encephalocele is an important prognostic factor. Based on the size, they can be labeled as small or giant cephaloceles. The term giant cephalocele is used when the size of the cephalocele is larger than the head size [23] (Fig. 7). Giant cephaloceles usually have a poor prognosis due to the herniation of large volumes of brain tissue.

\section{Content}

There are mainly four types of encephaloceles, which include meningocele, meningo-encephalocele, atretic encephalocele, and gliocele [24].

a. Skull defect + herniation of CSF, meninges, and neuroparenchyma represent meningoencephalocele. On MRI, it appears as a well-defined herniated sac with neuroparenchyma and CSF as its contents (Fig. 8a and b). The neuroparenchyma is frequently gliotic (Figs. 4 and 5).

b. Skull defect + herniation of only CSF and meninges represent meningocele. MRI appears well-defined sac with contents having signal intensity same as CSF on all sequences with a definable defect in the skull (Fig. 8c).

c. Atretic encephaloceles (Fig. 9) are form fruste of encephaloceles consisting of dura, fibrous tissue, and degenerated brain tissue; they are most common in the parieto-occipital area. They produce subscalp swelling which can be confused with other scalp masses.

d. Gliocele consists of a glial-lined cyst containing CSF (Fig. 6).

If the ventricle herniates into an encephalocele, it is termed meningo-encephalo-cystocele [12]. Encephaloceles contain brain tissue of varying signal intensities on MR imaging (hyperintensity on T2-weighted images may reflect gliosis) as well as spaces that are filled with cerebrospinal fluid. The nasal septum may appear deformed or truncated anteriorly by the sincipital cephalocele,
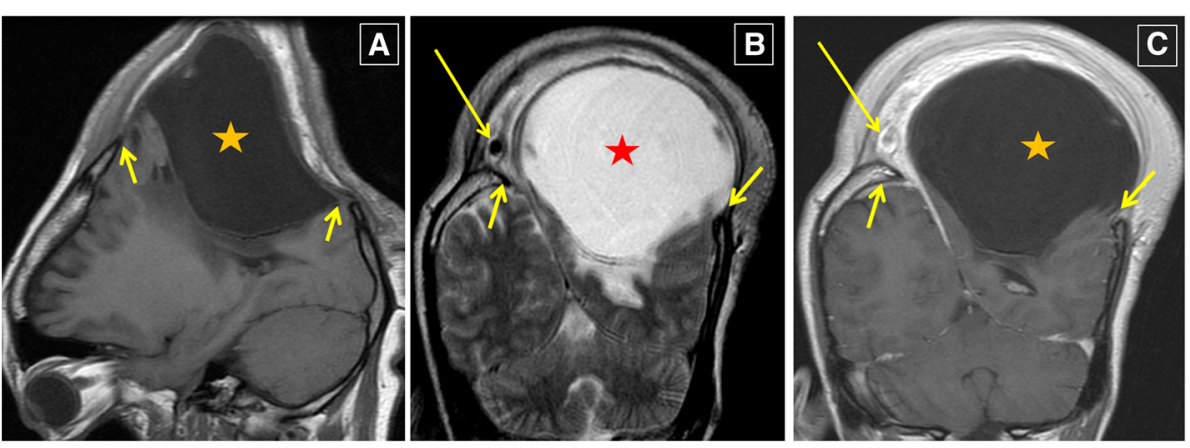

Fig. 6 Parietal encephalocele/gliocoele. (a) (sagittal T1 weighted), (b) (coronal T2 weighted), and (c) (T1-weighted coronal with gadolinium) images show herniation of the brain content through the defect in the left parietal bone (edges represented by short arrows). Note the presence of a large porencephalic cyst (star) at the site of herniation. The sagittal sinus (long arrows) has herniated into the sac 

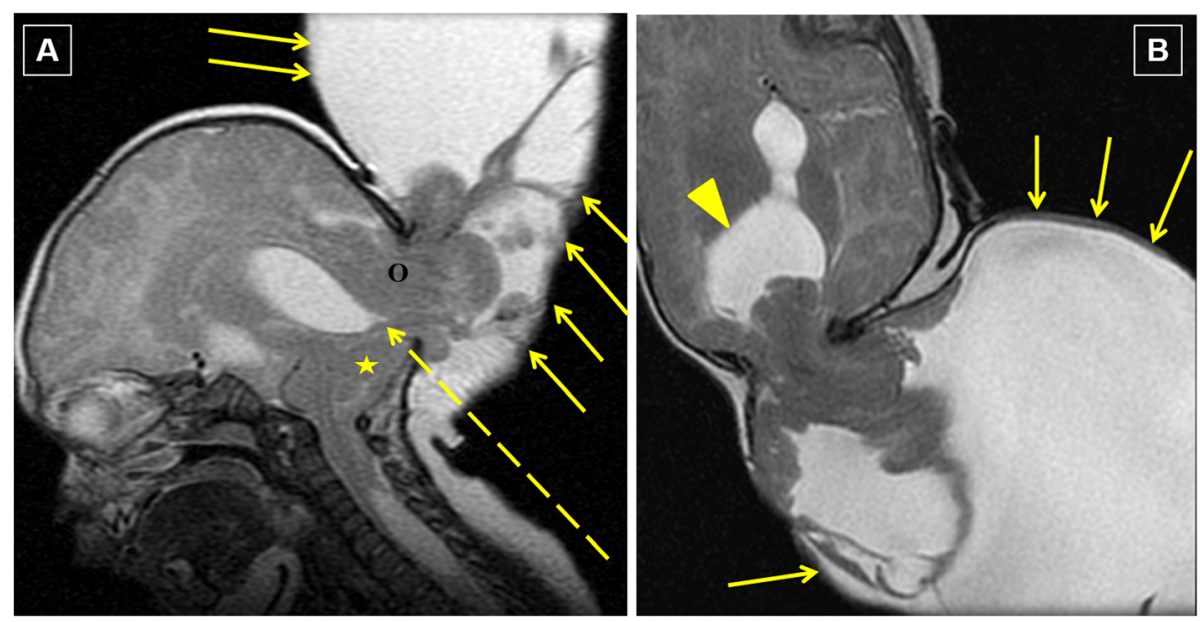

Fig. 7 Giant occipital encephalocele. (a) (T2-weighted sagittal) and (b) (T2-weighted axial) images: Note a large hernial sac (arrows) with herniation of posterior fossa content (star) and occipital lobes (O). There is herniation of the occipital horns into the hernial sac (dotted arrow). The size of the sac is larger than the size of the head. Note the deformed appearance of the lateral ventricle (arrowhead)

especially if the lesion is large. Tissues within the encephalocele are nonfunctional and may be resected with no adverse consequences. Enephaloceles have a direct connection to the intracranial cavity, and this connection must be obliterated to avoid potential future meningitis and abscess formation [25].

\section{Hydrocephalus}

The presence of hydrocephalus is another important prognostic factor. The occurrence of hydrocephalus is higher in posterior cephalocele and may occur due to torsion of the aqueduct of Sylvius or aqueductal stenosis [20]. Important imaging features that help the radiologists in the safe diagnosis of hydrocephalus are ventricular dilatation and rounding particularly the temporal horns, enlargement of the anterior and posterior recesses of the third ventricle, downward bulging of the floor of the third ventricle, and effacement of the sulci along the convexity.
Depending on the degree of the hydrocephalus and its effect on the neuroparenchyma, the patient might have to undergo shunting to relieve the pressure. The points to be addressed while reporting hydrocephalus are the level of ventricular dilatation, degree/severity of dilatation, effect on the neuroparenchyma, and presence of periventricular transependymal leak. The degree of the hydrocephalus can be quantified using several measurements/indices which will be useful during the follow-up studies. Some parameters which can be used are Evan's index (ratio of the maximum transverse diameter of the frontal horns to the maximum internal diameter of the skull at the same level), the ventricular angle (the angle between the frontal horns at the level of the foramina of Monroe), and frontal horn radius (widest diameter of the frontal horns obtained at an angle of $90^{\circ}$ to their long axis). Even diameter at the atrium level can be measured to use during follow-up studies [26].

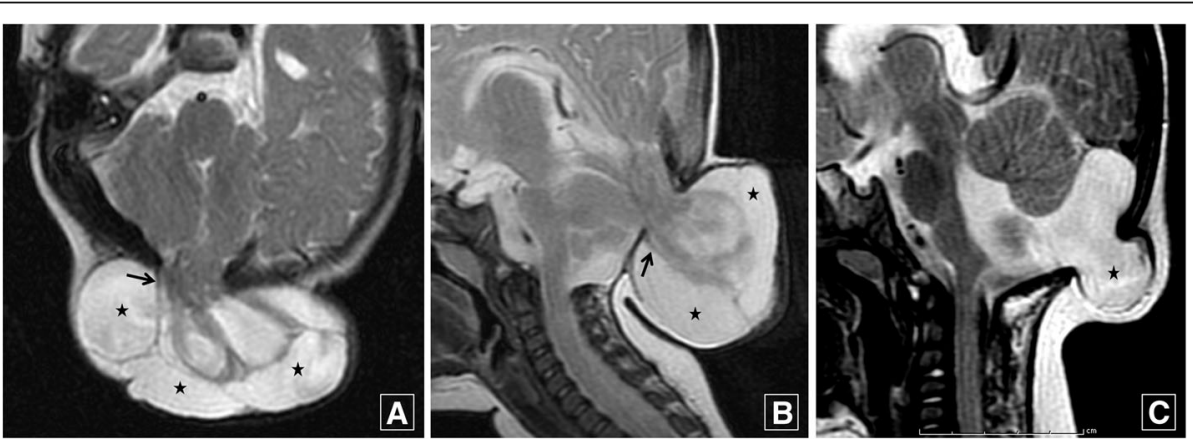

Fig. 8 Occipital meningo-encephalocele and occipital meningocele. (a) (T2-weighted axial) and (b) (T2-weighted sagittal) images show herniation of CSF (stars) and neuroparenchyma (arrow) through occipital bone defect suggestive of meningoencephalocele. (c) (T2-weighted sagittal) image shows herniation of only CSF (star) through occipital defect suggestive of meningocele 

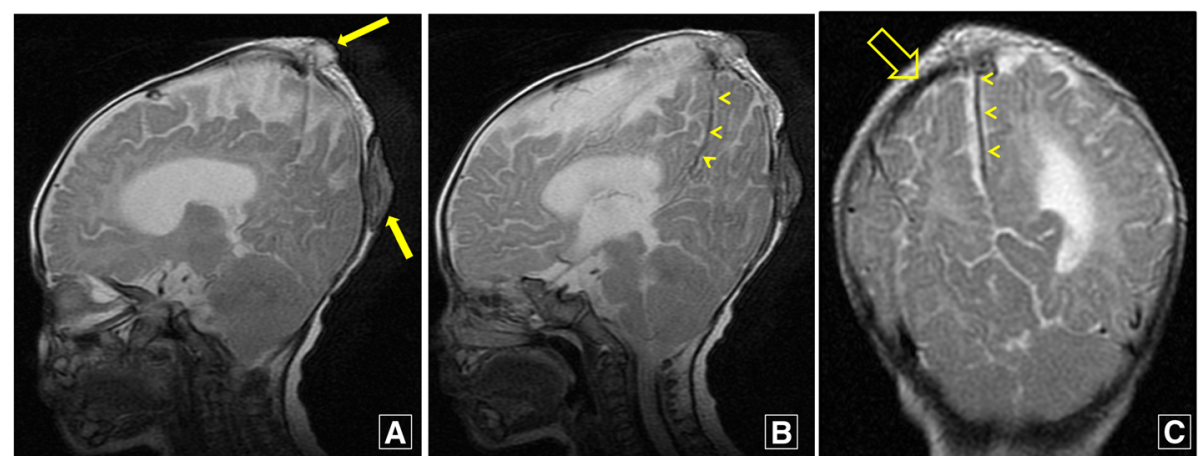

Fig. 9 Atretic encephalocele. (a) (T2-weighted sagittal image), (b) (T2-weighted sagittal image), and (c) (T2-weighted coronal image) show the presence of atretic encephalocele at the parietal and occipital locations (arrows). Note the vertical sigmoid sinus (persistent falcine sinus shown by arrowheads and vertical course of right transverse sinus shown by open arrow (not seen in its entire course on the single image). The left transverse sinus was hypoplastic

\section{Status of venous sinuses}

MR venogram and angiography are essential to assess the relationship of the dural sinuses and vessels to the hernia sac and to detect associated venous anomalies. Atretic is commonly associated with venous anomalies, most consistent among them is the presence of falcine sinus [27] (Fig. 9).

\section{Associated intracranial malformation (Fig. 10)}

Encephaloceles have a high prevalence of associated intracranial anomalies $[28,29]$. Sincipital encephaloceles have higher incidences of migrational anomalies (such as microcephaly, heterotropias, and schizencephaly), arachnoid cyst, and porencephalic cyst. Patients with occipital cephaloceles have higher probabilities of posterior fossa malformations which include Dandy-Walker malformation, Chiari malformation, and agenesis of the corpus callosum. Associated spinal dysraphism and vertebral anomalies need to be addressed due to their long-term effects on the patients. Frontal cephaloceles can be associated with the median cleft face syndrome, characterized by hypertelorism and median cleft lip or palate
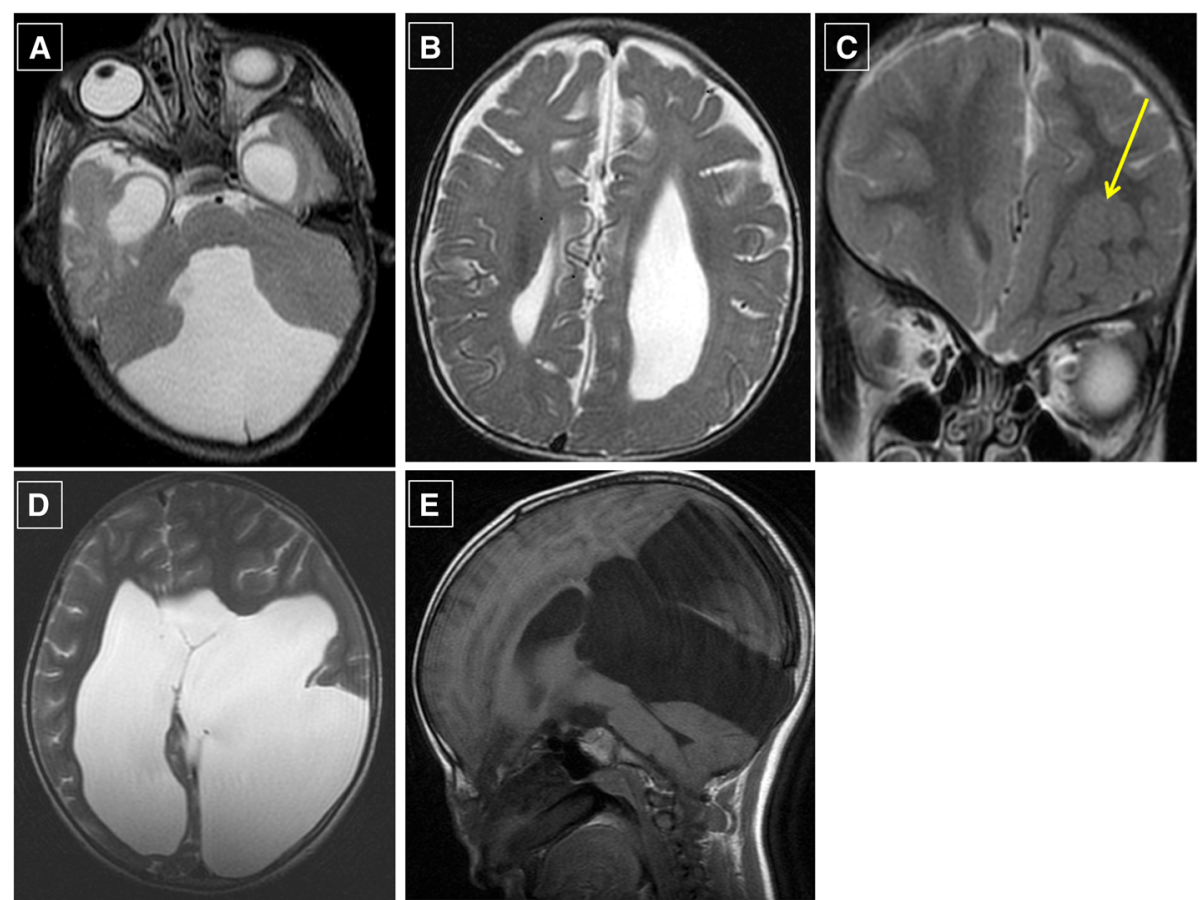

Fig. 10 Associated intracranial malformation. (a) (T2-weighted axial image): Dandy Walker malformation. (b) (T2-weighted axial image): Corpus callosal agenesis. (c) (T2-weighted coronal image): Heterotropia (arrow). (d) (T2-weighted axial image): Large open lip schizencephaly. (e) (T1weighted sagittal image): Posterior fossa arachnoid cyst 
[30]. It can be associated with other lesions of mesenchymal origin in the scalp like dermoid (Fig. 11).

\section{Differential diagnosis}

The main differential diagnosis to be considered in the case of sincipital cephalocele is nasal glioma and dermoid/epidermoid cyst. Nasal glioma (nasal glial heterotropia) consists of disorganized neuroparenchyma trapped in the prenasal space. They usually do not have intracranial communication; however, a fibrous stalk might extend via the foramen cecum. On MR imaging, it appears isointense to the cortex on T1W and T2W sequences or may have high signal intensity on T2W sequences as a result of gliosis. An encephalocele might also show a similar imaging picture; however, there will be definite evidence of intracranial extension demonstrated by widened foramen cecum/fonticulus frontalis and eroded/widened crista galli (Fig. 12). The basic embryology of encephalocele and nasal gliomas is the same; hence, nasal gliomas may also be associated with widened foramen cecum/fonticulus frontalis and eroded/ widened crista galli. In such scenarios, heavily T2weighted images or intrathecal contrast will show communication of the encephalocele with the subarachnoid space (in contrast to nasal gliomas). Nasal dermoid/epidermoid occurs due to trapping of ectodermal tissue in the region of the frontonasal diverticula. Dermoid occurs in the midline and shows the presence of fat within evident as hyperintense on T1-weighted images. Epidermoid appears similar to CSF on all pulse sequences and show diffusion restriction [7, 8, 28]. Other differential diagnoses of masses in the nasofrontal region include frontal sinus mucocele, neurinoma, hemangioma, and dacryocystocele. These can be differentiated from encephaloceles based on absent intracranial communication [7, 31]. Convexity encephaloceles can be differentiated from the scalp lesion such as dermoid, hemangioma, or neurofibroma based on demonstration of skull defect and intracranial communication. Also, the scalp lesions are not associated with intracranial malformations which commonly occur with encephaloceles. Basal encephaloceles should be differentiated from nasopharyngeal and nasal cavity masses. Sinus pericranii and dermoid cysts are the most common lesions that are confused with atretic parietal encephaloceles as scalp masses [32].

\section{Prognosis}

Factors affecting patient outcome are (1) location: Location of the hernia sac and its content is an important prognostic factor. The occipital encephaloceles have a poor prognosis. The herniated content in cases of occipital encephaloceles is mainly vermis and rarely cerebellum to a varying extent; however, occasionally occipital lobes do herniate (Fig. 10). Such patients have the risk of potential vision loss because the herniated brain tends to undergo gliosis. The prognosis for the sincipital encephalocele patients is generally good and is usually associated with normal intelligence and motor development. (2) Size of sac and amount of brain tissue: Prognosis of the patients also depends on the size of the sac and the amount of brain tissue herniated, (3) hydrocephalus, (4) associated malformation, and (5) associated infections $[33,34]$.

\section{Treatment}

Surgical management at the earliest is the key factor to avoid infections, worsening hydrocephalus, and distortion
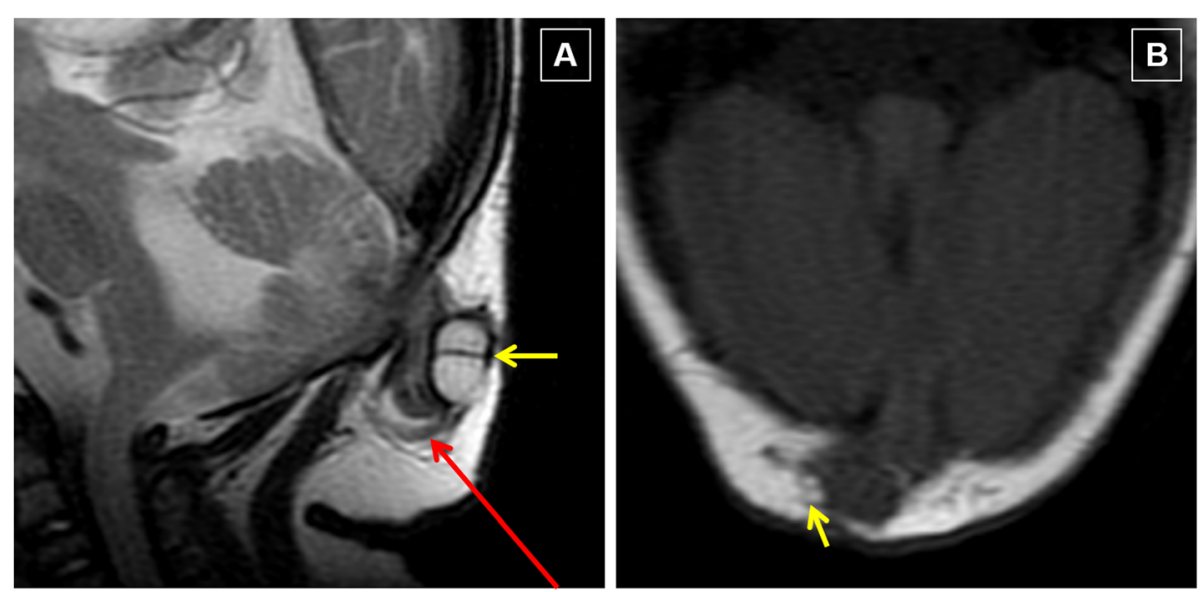

Fig. 11 Occipital meningoencephalocele with an associated dermoid. (a) (T2-weighted sagittal) shows occipital meningoencephalocele (long arrow) with an associated T2 hyperintense cystic appearing lesion (short arrow) along the peripheral aspect of the herniated sac. (b) (T1-weighted axial) image shows $\mathrm{T} 1$ hyperintense focus (short arrow) along the peripheral aspect of the herniated sac. Histopathology confirmed this lesion to be a dermoid 

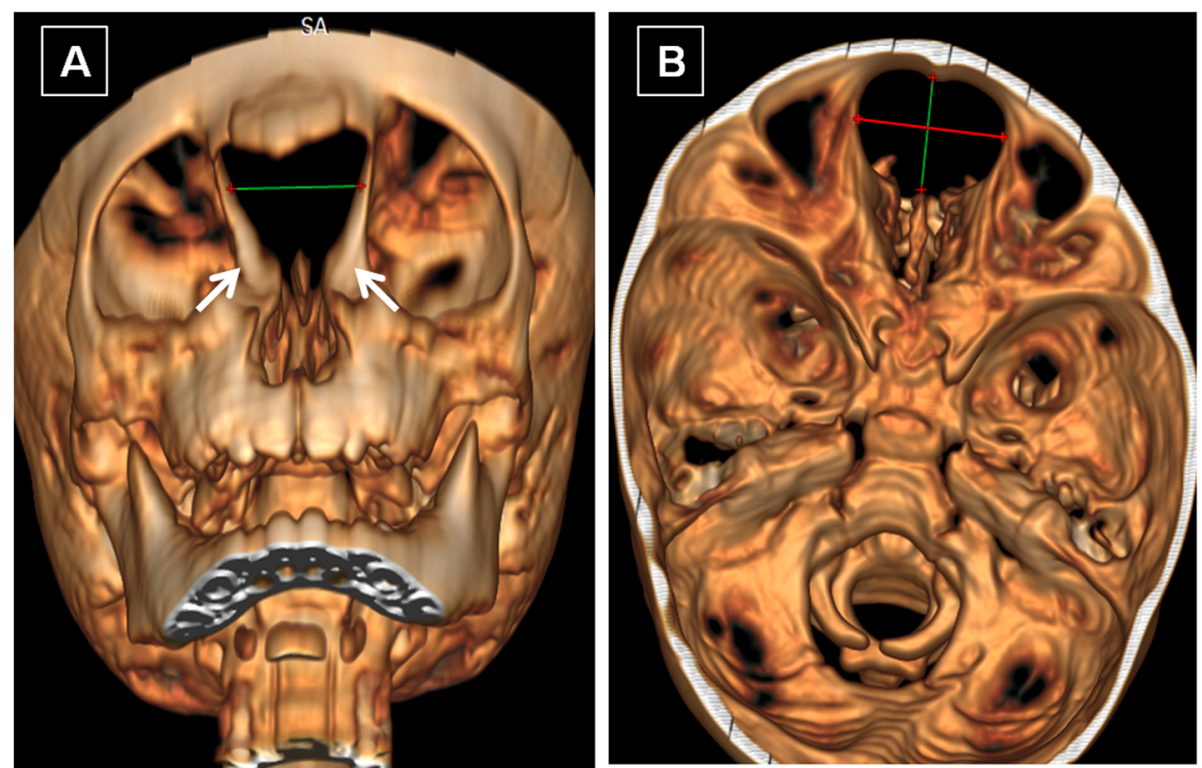

Fig. $12 C T$ scan with volume rendered technique. (a) represents defect seen from below and (b) represents defect seen from above. CT scan with volume rendered technique shows presence of large anterior skull base defect in midline marked by calipers with widely separated and deformed crista galli shown by white arrows shown in (a)

of the facial anatomy. Treatment includes removal of the sac and herniated neuroparenchyma and reconstruction of the bony defect. Associated hydrocephalus if present can be addressed with shunting before the management of encephalocele. In cases of skull base encephalocele, operative approaches for repair include open transcranial, transsphenoidal microscopic, or endoscopic trans-nasal approach [35]. Some authors have suggested an open transcranial approach for patients with a large bone defect and those associated with intracranial lesions [36, 37]. The endoscopic transnasal approach is also an effective and safe method for patients with skull base encephalocele. The endoscopic approach has a good success rate with lower perioperative mortality and lower incidence of postoperative complications such as meningitis, CSF leak, and sepsis. During the endoscopic approach, damage to the olfactory nerve can also be avoided [35]. During the author's personal observations, cases of occipital encephaloceles underwent excision of the sac, repair, and cranioplasty. Sincipital encephaloceles underwent bi-frontal craniotomy with excision of the sac and anterior cranial fossa base repair with vascularized pericranial graft. Patients with basal encephaloceles underwent frontal craniotomy followed by excision and intradural ACF base carpeting with vascularized pericardial graft. A ventriculoperitoneal shunt was done in 6 patients. A cysto-peritoneal shunt was done in 1 patient.

\section{Prevention}

Since postulated mechanisms for encephalocele is neural tube defects, it cannot be prevented; however, the incidence can be reduced with folic acid supplementation [38]. The main goal should be early diagnosis and treatment to avoid complications. A cesarian delivery will reduce the chances of head trauma.

\section{Conclusion}

Encephalocele has always been a subject of predicament for radiologists. Understanding the relevant terminologies, anatomy, imaging protocols, classification, associated malformations/anomalies, and imaging prognostic factors will help to methodically approach each case and provide a systematic and comprehensive report.

\section{Reporting template}

1) Age and sex: months/years and $M / F$

2) Clinical indications

3) MRI sequences: Sagittal/coronal/axial T1/T2 sequences, FLAIR axial, MR venogram/angiogram, MPRAGE, corona heavily weighted T2 sequence.

4) Location of the lesion-(anterior) (parietal) (occipital) (lateral)

Anterior-(sincipital) (basal)

Sincipital (frontoethmoidal) (interfrontal) Frontoethmoidal (nasofrontal) (nasoethmoidal) (nasoorbital) Basal (transethmoidal) (sphenoethmoidal) (sphenoorbital) (transsphenoidal) Transsphenoidal (intrasphenoidal) (true transsphenoidal)

Parietal 
Occipital (supratorcular) (infratorcular)

5) Size of the sac-AP $\times$ SI $\times$ TR

6) Size of the calvarial defect

7) Contents of the sac

Meningocele +/-

Meningo-encephalocele $+/-$

Atretic encephaloceles +/-

Gliocele +/-

Meningo-encephalo-cystocele+/-

8) Hydrocephalus

Level of dilatation (lateral ventricle) (third ventricle) (aqueduct)

(Evan's index) (largest diameter at atrium) (ventricular angle) (frontal horn radius)

Periventricular transependymal leak $+/-$

Mass effect on neuroparenchyma $+/-$ (severity)

9) Associated malformation $+/$ - (corpus callosal agenesis) (cortical migrational abnormality) (DandyWalker malformation) (hypoplasia of pons and cerebellum) (arachnoid cyst) (porencephalic cyst) (tonsillar herniation)

Cortical migrational abnormality (microcephaly)

(heterotropia) (schizencephaly) (any other)

10) Status of the venous sinuses

Herniation of the sinus +/-

Which sinus has herniated (sagittal) (transverse) (torcula herophilli) (sigmoid)

Associated venous anomaly like persistent falcine sinus

11) Associated infection $+/-$, described the findings

12) Associated spinal pathology $+/-$, describe the findings

\section{Abbreviations}

MRI: Magnetic resonance imaging; CT: Computed tomography; FLAIR: Fluid attenuated inversion recovery sequence; MPRAGE: Magnetization prepared rapid gradient echo sequence; CSF: Cerebrospinal fluid

\section{Acknowledgements}

Not applicable.

\section{Authors' contributions}

NP, AJ, and SV have given substantial contribution in the conception, design of the work, the acquisition, and interpretation of data. Each author has helped in drafting the work or revising critically important intellectual content. All authors have read and approved the final version of the manuscript.

\section{Funding}

There is no specific grant from any funding agency in the public, commercial, or not-for-profit sectors.

\section{Availability of data and materials}

The data sets used and/or analyzed during the current study are available from the corresponding author on reasonable request.

\section{Declarations}

Ethics approval and consent to participate

Not applicable

\section{Consent for publication}

Not applicable

\section{Competing interests}

The authors declare that they have no competing interests.

\section{Author details}

${ }^{1}$ Department of Radio-diagnosis, Goa Medical College, Bambolim, Goa 403 202, India. ²Department of Radio diagnosis, Sri Sathya Sai Institute of Higher Medical Sciences, Whitefield, Bengaluru, India.

Received: 12 January 2021 Accepted: 4 April 2021

Published online: 15 April 2021

References

1. Barkovich AJ (2005) Congenital anomalies of the spine. In: Pediatric neuroradiology, 4th edn. Lippincott Williams \& Wilkins, Philadelphia, pp 801-868

2. Nakatsu T, Uwabe C, Shiota K (2000) Neural tube closure in humans initiates at multiple sites: evidence from human embryos and implications for the pathogenesis of neural tube defects. Anat Embryol (Berl) 201(6):455-466. https://doi.org/10.1007/s004290050332

3. Van Allen M, Kalousek D, Chernoff $G$ et al (1993) Evidence for multisite closure of the neural tube in humans. Am J Med Genet 47(5):723-743. https://doi.org/10.1002/ajmg.1320470528

4. Gluckman TJ, George TM, McLone DG (1996) Postneurulation rapid brain growth represents a critical time for encephalocele formation: a chick model. Pediatr Neurosurg 25(3):130-136. https://doi.org/10.1159/000121110

5. Marin-Padilla M (1980) Morphogenesis of experimental encephalocele (cranioschisis occulta). J Neurol Sci 46(1):83-99. https://doi.org/10.1016/ 0022-510X(80)90045-3

6. Bhagwati SN, Mahapatra AK (1999) Encephalocele and anomalies of the scalp. In: Choux M, Di Rocco C, Hockley AD, Walker JL (eds) Pediatric neurosurgery. Churchill Livingstone, London, pp 101-120

7. Lowe LH, Booth TN, Joglar JM, Rollins NK (2000) Midface anomalies in children. RadioGraphics 20(4):907-922. https://doi.org/10.1148/radiogra phics.20.4.g00j107907

8. Barkovich AJ, Vandermarch P, Edwards MSB, Cogen PH (1991) Congenital nasal masses: CT and MR imaging features in 16 cases. AJNR Am J Neuroradiol 12(1):105-116

9. Diebler C, Dulac O (1983) Cephaloceles: clinical and neuroradiological appearance. Associated cerebral malformations. Neuroradiology 25:199-216

10. Mahapatra AK (2011) Anterior encephalocele - AllMS experience a series of 133 patients. J Pediatric Neurosci 6(suppl 1):S27-S30. https://doi.org/10.41 03/1817-1745.85706

11. Phatak SV, Rajderkar D (2006) Rare type of frontal encephalocele (paramedian). Ind J Radiol Imag 16(3):309-311. https://doi.org/10.4103/ 0971-3026.29003

12. Suwanwela C, Suwanwela N (1972) A morphological classification of sincipital encephalomeningoceles. J Neurosurg 36(2):201-211. https://doi. org/10.3171/jns.1972.36.2.0201

13. Hoving EW (2000) Nasal encephaloceles. Childs Nerv Syst 16(10-11):702-706. https://doi.org/10.1007/s003810000339

14. Naidich TP, Zimmerman RA, Bilaniuk LT (1996) Midface: embryology and congenital lesions. In: Som PM, Curtin HD (eds) Head and neck imaging, vol 2. Mosby, St Louis, pp 3-60

15. Martinez-Lage JF, Poza M, Sola J, Soler CL, Montalvo CG, Domingo R et al (1996) The child with a cephalocele: etiology, neuroimaging, and outcome. Childs Nerv Syst 12(9):540-550. https://doi.org/10.1007/BF00261608

16. Sharma RR, Mahapatra AK, Pawar SJ, Thomas C, Al-Ismaily M (2002) Transsellar trans-sphenoidal encephaloceles: report of two cases. J Clin Neurosci 9(1):89-92. https://doi.org/10.1054/jocn.2001.0861 
17. Lai SY, Kennedy DW, Bolger WE (2002) Sphenoid encephaloceles: disease management and identification of lesions within the lateral recess of the sphenoid sinus. Laryngoscope 112(10):1800-1805. https://doi.org/10.1097/ 00005537-200210000-00018

18. Pollock JA, Newton TH, Hoyt WF (1968) Transsphenoidal and transethmoidal encephaloceles. Radiology 90(3):442-453. https://doi.org/10.1148/90.3.442

19. Abiko S, Aoki H, Fudaba H (1988) Intrasphenoidal encephalocele: report of a case. Neurosurgery 22(5):933-936. https://doi.org/10.1227/00006123-1 98805000-00024

20. Verma SK, Satyarthee GD, Singh PK, Sharma BS (2013) Torcular occipital encephalocele in infant: report of two cases and review of literature. J Pediatr Neurosci 8(3):207-209. https://doi.org/10.4103/1817-1745.123666

21. Fitzpatrick E, Miller RH (1996) Congenital midline nasal masses: dermoids, gliomas, and encephaloceles. J La State Med Soc 148(3):93-96

22. Coates H (1992) Nasal obstruction in the neonate and infant. Clin Pediatr 31(1):25-29. https://doi.org/10.1177/000992289203100106

23. Borkar S, Mahapatra A (2012) Encephaloceles: a study of 110 patients operated on at AllMS. J Neurol Surg B 73:A520

24. Naidich TP, Altman NR, Braffman BH, McLone DG, Zimmerman RA (1992) Cephaloceles and related malformations. AJNR Am J Neuroradiol 13(2):655-690

25. Valencia MP, Castillo M (2008) Congenital and acquired lesions of the nasal septum: a practical guide for differential diagnosis. Radiographics 28(1):205224. https://doi.org/10.1148/rg.281075049

26. Raybaud C (2018) Radiology of hydrocephalus. In: Cinalli G, Ozek M, SainteRose C (eds) Pediatric Hydrocephalus. Springer, Cham, pp 1-122. https://doi. org/10.1007/978-3-319-31889-9 44-1.

27. Brunelle F, Baraton J, Renier D, Teillac D, Simon I, Sonigo P, Hertz-Pannier L, Emond S, Boddaert N, Chigot V, Lellouch-Tubiana A (2000) Intracranial venous anomalies associated with atretic cephaloceles. Pediatr Radiol 30(11):743-747. https://doi.org/10.1007/s002470000328

28. Morón FE, Morriss MC, Jones JJ, Hunter JV (2004) Lumps and bumps on the head in children: use of CT and MR imaging in solving the clinical diagnostic dilemma. Radiographics 24(6):1655-1674. 15537975. https://doi. org/10.1148/rg.246045034

29. Achar SV, Dutta HK (2016) Sincipital encephaloceles: a study of associated brain malformations. J Clin Imaging Sci 6:20. https://doi.org/10.4103/21567514.183040

30. Fitz CR (1982) Midline anomalies of the brain and spine. Radiol Clin North Am 20(1):95-104 Epub 1982/03/01

31. Dhirawani RB, Gupta R, Pathak S, Lalwani G (2014) Frontoethmoidal encephalocele: case report and review on management. Ann Maxillofac Surg 4(2):195-197. https://doi.org/10.4103/2231-0746.147140

32. Burrows $P E$, Konez $\mathrm{O}$, Bisdorff $\mathrm{A}$ (2003) Venous variations of the brain and cranial vault. Neuroimag Clin N Am 13(1):13-26. https://doi.org/10.1016/s1 052-5149(02)00061-8

33. Chateil JF, Girault JM, Pedespan JM, Dousset V, Castell JF, Diard F (1994) Agyria-pachygyria and pachygyria in children. Contribution of imaging. Arch Pediatr 1(6):551-560

34. Kiymaz N, Yilmaz N, Demir I, Keskin S (2010) Prognostic factors in patients with occipital encephalocele. Pediatr Neurosurg 46(1):6-11. https://doi.org/1 $0.1159 / 000314051$

35. Komotar RJ, Starke RM, Raper DM, Anand VK, Schwartz TH (2013) Endoscopic endonasal versus open repair of anterior skull base CSF leak, meningocele, and encephalocele: a systematic review of outcomes. J Neurol Surg A Cent Eur Neurosurg 74(4):239-250. https://doi.org/10.1055/s$0032-1325636$

36. Scholsem M, Scholtes F, Collignon F, Robe P, Dubuisson A, Kaschten B, Lenelle J, Martin D (2008) Surgical management of anterior cranial base fractures with cerebrospinal fluid fistulae: a single-institution experience. Neurosurgery 62(2): 463-469. https://doi.org/10.1227/01.neu.0000316014.97926.82

37. Hubbard JL, McDonald TJ, Pearson BW, Laws ER Jr (1985) Spontaneous cerebrospinal fluid rhinorrhea: evolving concepts in diagnosis and surgical management based on the Mayo Clinic experience from 1970 through 1981 Neurosurgery 16(3):314-321. https://doi.org/10.1227/00006123-198503000-00006

38. Kabré A, Zabsonre DS, Sanou A, Bako Y (2015) The cephaloceles: a clinical, epidemiological and therapeutic study of 50 cases. Neurochirurgie 61(4): 250-254. https://doi.org/10.1016/j.neuchi.2015.03.011

\section{Publisher's Note}

Springer Nature remains neutral with regard to jurisdictional claims in published maps and institutional affiliations.

\section{Submit your manuscript to a SpringerOpen ${ }^{\circ}$ journal and benefit from:}

- Convenient online submission

- Rigorous peer review

- Open access: articles freely available online

- High visibility within the field

- Retaining the copyright to your article

Submit your next manuscript at $\boldsymbol{\nabla}$ springeropen.com 